\title{
Ocupação urbana, redes sociais e territorialização da resistência: o caso de Aparecida de Goiânia, Brasil
}

\author{
Urban occupation, social medias and the resistance territorialization: \\ the case of Aparecida de Goiânia, Brazil
}

Sandro de Oliveira Safadi

Instituto Federal de Goiás (IFG), Anápolis, GO, Brasil

\section{Resumo}

É assumindo a cidade como o lócus fundamental das tensões contemporâneas que as análises aqui presentes se sustentam. 0 itinerário investigativo buscou explicitar como a cultura urbana, entendida como movimento cotidiano central das cidades, estabelece com a paisagem uma relação de resistência à dinâmica global que penetra os lugares. 0 objeto de estudo em questão é Aparecida de Goiânia, cidade partícipe da Região Metropolitana de Goiânia, no Estado de Goiás. 0 estudo se debruçou sobre as materialidades culturais que são percebidas na paisagem de Aparecida de Goiânia, entrelaçando apontamentos teóricos e conteúdos obtidos por meio de entrevistas e questionários realizados com atores sociais diretamente envolvidos com a cultura não oficializada. Entre março de 2013 e julho de 2015, identificaram-se mais de 300 grupos/artistas e cerca de 80 entidades e 70 locais que dinamizam sistematicamente a cultura no município de Aparecida de Goiânia. Agregaram-se ainda à pesquisa empírica 121 grupos e artistas que possuem perfis em redes sociais digitais, extraídos do universo identificado. A análise, portanto, permeia também o modo como essas redes fomentam mecanismos de fortalecimento da dinâmica cultural no processo de configuração das materialidades presentes na paisagem. Essas materialidades/objetos absorvem os fluxos de racionalidades locais produzidos pelos indivíduos e pelos grupos organizados; assim, com a participação nas referidas redes sociais digitais, estimula-se o pertencimento e fundam-se territorialidades resistentes na cidade.

Palavras-chave: Cultura urbana. Redes sociais digitais. Territorialização da resistência.

\section{Abstract}

The analyses here proposed are based on the assumption of the city as the fundamental locus of contemporary tensions. The investigational itinerary tried to explain how the urban culture, considered the central move that daily takes place within the city, establishes with the landscape a relation of resistance against the global dynamics that penetrates places. The object of our study is Aparecida de Goiânia, a city comprised in the metropolitan region of Goiânia-GO. This study has leaned over the cultural materialities perceived in the landscape of Aparecida de Goiânia, intertwining theoretical approaches and contents gathered through interviews and questionnaires carried out with social actors directly involved in non-official culture. Between March 2013 and June 2015, more than three hundred groups/artists were identified, and about eighty institutions and seventy venues that

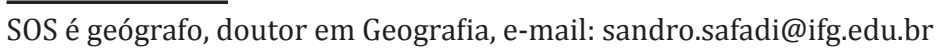


systematically stimulate cultural life in the municipality of Aparecida de Goiânia. We have also added to the empirical research, one hundred and twenty one groups and artists who have profiles in digital social medias. The analysis, in this case, also permeates how digital social medias foster mechanisms of strengthening the cultural dynamics in the process of the lascape's materialities configuration. This materiality, objects, absorb the flows of local rationalities produced by individuals and organized groups, that the participation in these digital social medias encourage belonging, building territorialities resistant in the city.

Keywords: Urban culture. Digital social medias. Territorialization of resistance.

\section{Considerações iniciais}

A cidade manifesta as agruras do nosso tempo e vive a tensão contemporânea expressa nos conflitos estabelecidos entre dinâmicas impostas globalmente e dinâmicas locais. Este trabalho se sustenta na compreensão de que a cidade é o lócus primordial desses conflitos, seja em sua materialidade captada na paisagem, seja na carga de símbolos que a permeia. Nessa medida, além de enfrentar a relação entre o global e o local pelo viés da técnica, há, neste trabalho, o interesse em significar essa relação em meio ao processo de ocupação imaterial da cidade.

Esta investigação propõe que tal enfrentamento seja radicalizado a partir da cultura em suas manifestações propriamente ditas (artistas, grupos e entidades culturais) e também tendo em perspectiva os lugares que a dinamizam, além de se debruçar sobre mecanismos de organização em rede que estabelecem territorialidades na cidade.

Neste texto, cidade e cultura são visitadas com o intuito de averiguar como os fluxos de tensão entre os componentes vindos de uma dinâmica cultural global e o conjunto de particularidades locais estimulam resistências. É válido ressaltar aqui que a ideia-chave que permeia os conceitos de território e também de territorialidade se alicerça não somente na perspectiva funcional político-administrativa, mas se estende ao campo simbólico de lutas subalternas, como um continuum (Haesbaert, 2014). A cultura enquanto expressão materializada na paisagem é tratada como uma das formas características pelas quais atores sociais tornam-se partícipes e fundam modos de vida que se expressam no cotidiano das cidades. 0 objeto de estudo em questão é Aparecida de Goiânia (Figura 1), cidade incrustada na Região Metropolitana de Goiânia, capital do Estado de Goiás, localizada no Centro-Oeste brasileiro, distante $220 \mathrm{Km}$ da capital federal, Brasília. Os dados aqui apresentados são frutos de dois projetos de pesquisa ${ }^{1}$ orientados no âmbito do Programa Institucional de Bolsas de Iniciação Científica para o Ensino Médio (PIBIC-EM), do Conselho Nacional do Desenvolvimento Científico e Tecnológico (CNPQ), desenvolvidos por alunos do Instituto Federal de Goiás entre março de 2013 e julho de 2015. Especificamente entre agosto de 2014 e julho de 2015, o trabalho voltou-se para o estudo do modo como as redes sociais interferem nos comportamentos dos atores envolvidos com a cultura de Aparecida de Goiânia e de que forma elas podem se constituir como mecanismos de auxílio às estratégias de territorialização de processos resistentes.

Este texto apresenta uma reflexão teórica que é auxiliada por resultados obtidos mediante a aproximação investigativa com 300 grupos e artistas, 80 entidades e instituições, e outros 70 locais dinamizadores da cultura. Mesmo compreendendo que esses números sejam expressivos diante da falta de dados oficiais, ressalta-se que é necessário que eles sejam considerados não apenas em sua dimensão meramente quantitativa, como se percentualmente representassem a cultura de uma dada realidade. Os dados quantitativos alcançados devem ser compreendidos como componentes indutores de reflexões qualitativas para a extração de entendimentos que possam, em alguma medida, evidenciar nuanças da expressão cotidiana da cultura na urbanidade atual de Aparecida de Goiânia.

\footnotetext{
${ }^{1}$ Os projetos citados foram desenvolvidos entre março de 2013 e julho de 2015, e seus respectivos títulos são: "Entre o global e o local: Estudo sobre a paisagem de Aparecida de Goiânia, a partir das práticas culturais urbanas", desenvolvido pelos alunos Éder Bruno de Araújo e Eduarda Santos Silva, e "Resistir na cidade global: Estudo sobre os movimentos culturais autênticos de Aparecida de Goiânia dinamizados pela utilização de ferramentas digitais", desenvolvido pelos alunos Henrique Rodrigues Hermano e Emilly Caroline Barbosa Brito.
} 


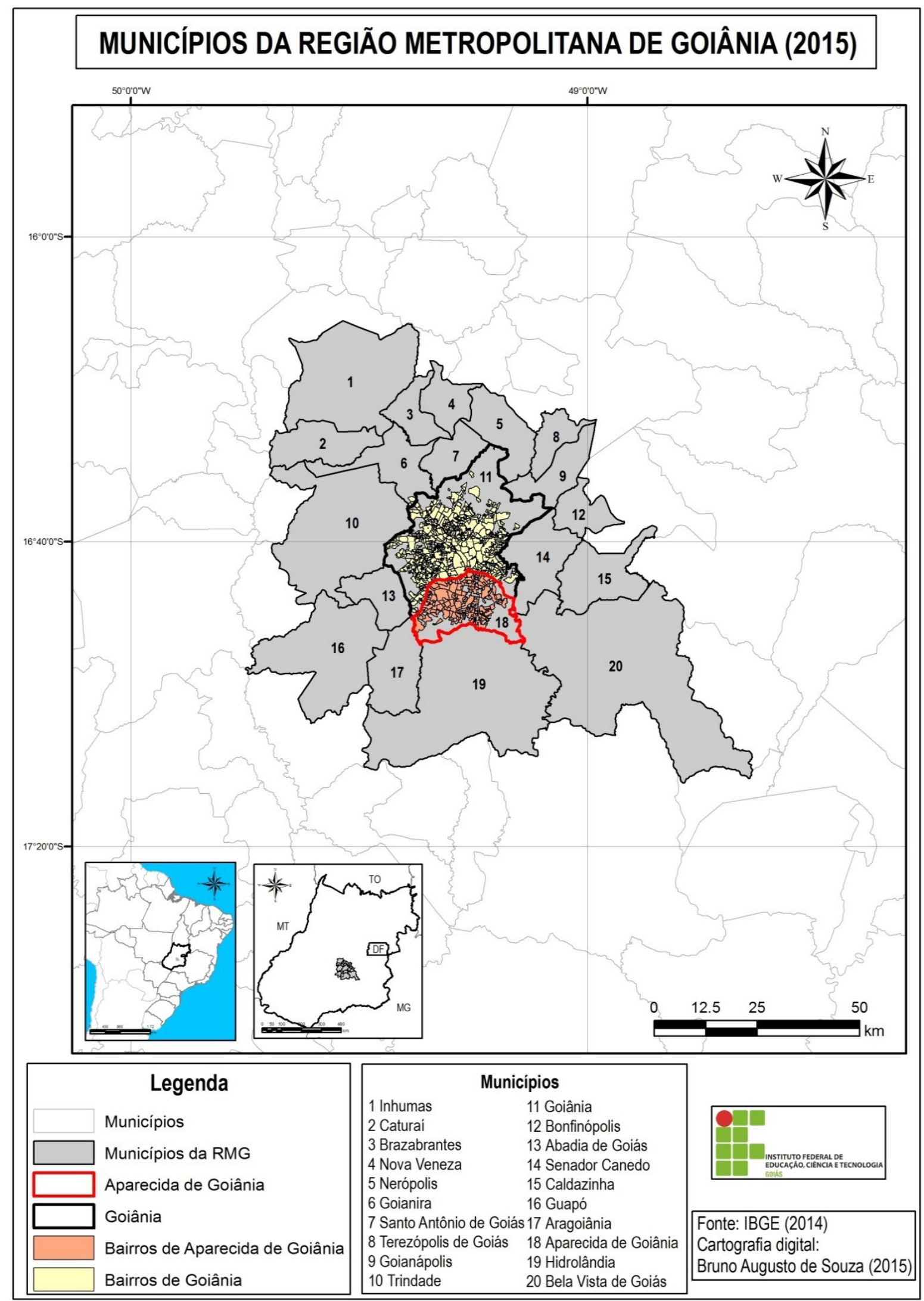

Figura 1 - Localização do município de Aparecida de Goiânia na Região Metropolitana de Goiânia (RMG), Estado de Goiás Fonte: IBGE (2014). 
O interesse, portanto, em relação a este universo constituído por artistas, grupos e entidades/instituições está articulado ao acontecimento da prática cultural na cidade de Aparecida de Goiânia, em suas possíveis interfaces com a ocupação urbana. Agrega-se ainda uma análise sobre o comportamento de 121 grupos e artistas que possuem perfis em redes sociais digitais extraídos do universo inicial. Vislumbrou-se, assim, outra dimensão analítica que permite esmiuçar os mecanismos de fortalecimento da cultura urbana em rede como processo de resistência técnica e simbólica na cidade.

A eleição das redes sociais digitais enquanto foco de análise se deu pela evidente utilização desses mecanismos de comunicação, seja pelos grupos e artistas, seja pelas entidades que dinamizam a cultura na cidade, como principal veículo de divulgação da prática cultural. 0 diálogo direto com o público pelas redes sociais facilita os contatos pessoais nos momentos de exposição da prática. Estas, nesse contexto, contribuem para que o trabalho dos grupos e dos artistas apareça na paisagem da cidade com um grau de intimidade já estabelecido previamente de maneira digital.

Essa aparição das práticas culturais desenvolvidas pelos grupos e pelos indivíduos na paisagem da cidade permite que os objetos carreiem racionalidades locais. A casa, o bar, a igreja, a praça, a rua, a feira, quando tornam-se locais de práticas culturais e potencializados pelo convívio digital, transformam-se em lugares de estímulo ao pertencimento. Em meio aos fluxos que partem da intimidade do lar, passando pelo convívio dos grupos em locais privados e públicos, surgem territorialidades resistentes. A cidade, nesse contexto, passa por um conflito entre horizontalidades e verticalidades (Santos, 1999), pois há um arranjo, nem sempre pacífico e solidário, entre a racionalidade proveniente de uma ordem global, estrangeira, em contato com os diversos modos de configuração de racionalidades forjadas nos lugares. Nessa perspectiva, as territorialidades alicerçadas pela cultura são elevadas à condição de geradoras de autenticidades.

A cidade, como concretude da experiência e, que se desdobra como urbana é, nessa medida, a possibilidade do estabelecimento de focos de resistência articulados por aqueles que não participam como atores hegemônicos dos acordos globais. Em última análise, a cidade torna-se um lugar privilegiado para a própria existência não somente por ser o lócus substancial do conjunto de moradas dos humanos, mas, acima de tudo, por trazer em sua raiz o espírito do tempo moderno, por trazer o significado da realização do projeto humano dos últimos séculos, especialmente do século XX até os dias atuais (Souza, 1997).

Nessa cidade, ponto de tensão entre o local e o global, a cultura contemporânea se expressa na vida cotidiana em consonância com elementos que surgem diretamente vinculados à rede mundial de computadores. Os grupos, os artistas e as instituições geradoras de cultura utilizam-se das redes sociais digitais como seus novos modos de conquista dos lugares. Em meio aos processos de massificação da cultura, surgem articulações identitárias preenchidas de informações que foram lapidadas pelo convívio digital, haja vista os inúmeros casos de artistas que, primeiramente, ganham notoriedade nas redes sociais digitais para, posteriormente, estabelecerem contatos com seu público na concretude da cidade.

Nos modos característicos de convivência nas redes sociais, os quais se transformam em espécies de ritos digitais de contato, estão presentes fragmentos do mundo vivido nas ruas, não em sua completude e em sua concretude evidenciadas nas próprias ruas, mas também não discretos o suficiente para serem ignorados. Se a cultura de massa gera materialidades e convivências específicas, pode-se inferir que ela é "campo transversal" e ao mesmo tempo geradora e destruidora de "identidades" (Serpa, 2007). Destroem-se identidades na mesma intensidade em que se fundam novas alternativas para os modos específicos de existência que são elaborados na zona de conflito.

Em cada paisagem vivida/observada, ressurgem os motes clarificadores dos corpos que ali habitam e também dos símbolos peculiares de cada localidade; é na profundidade da paisagem que crispa a existência (Besse, 2006). Nesse instante de criação de novas identidades e de formação de existências mundanas alternativas, altera-se a luta urbana. As marcas e as matrizes como dimensões da paisagem (Berque, 2004) são reconfiguradas. Essas reconfigurações que nutrem outras formas identitárias e existenciais ocorrem em estágio ainda inicial em Aparecida de Goiânia. 0 contato com a esfera digital acelera esse movimento, estimulando outras formas de permanências locais.

Buscando evidenciar esses traços do mundo contemporâneo em Aparecida de Goiânia, o texto se organiza, primeiramente, situando esta cidade em seu contexto regional. Posteriormente, apresentam-se os 
dados obtidos empiricamente como elementos para corroborar a tese do texto, qual seja, a possibilidade de as redes sociais digitais se tornarem mecanismos de fortalecimento de territorialidades resistentes. Os dados são apresentados em alguns gráficos obtidos em duas amostras extraídas de um universo de pesquisa constituído por artistas, grupos e entidades/localidades pesquisados. Nas etapas finais do texto, busca-se expor algumas reflexões a partir da confluência entre conceitos oriundos das discussões acerca da territorialidade e resistência, para se pensar tópicos específicos enaltecidos, na caracterização dos locais de cultura que habitam a cidade.

\section{Aparecida de Goiânia, uma cidade em meio à metropolização de Goiânia}

As primeiras moradias e situações urbanas em Aparecida de Goiânia datam da década de 1920, antes da própria viabilização política de Goiânia como capital do Estado de Goiás, algo que se deu apenas na década seguinte. A consolidação da capital em 1933 desencadeou um acelerado afloramento da identidade urbana na região e este permaneceu ainda latente em Aparecida de Goiânia até a emancipação do município em 1963.

Foi somente com a intensificação do processo de metropolização da capital do Estado de Goiás que se tornou possível pensar nos movimentos urbanos desenvolvidos em Aparecida de Goiânia como reflexos diretos da influência de sua localização. Os dados populacionais demonstram claramente um gatilho demográfico após a década de 1970. Este se mantém até os dias atuais, fazendo com que Aparecida de Goiânia, que possuía 7.470 habitantes em 1970, elevasse esse número para 42.627 na década seguinte e para 178.483 na década de 1990 , chegando a 336.392 em 2000 e 455.675 em 2010.

Esse expressivo crescimento populacional se justifica exatamente pela forma como se deu a expansão urbana de Goiânia, a qual se manteve em franco desenvolvimento para o sul, tendo na cidade de Aparecida de Goiânia o seu eixo. Deflagram-se nesse movimento duas vivências urbanas distintas nessa cidade: a primeira tendo um fluxo de acontecimentos vinculados quase que exclusivamente à capital do Estado e a segunda desenvolvendo fluxos característicos de uma cidade substancialmente menor. As Figuras 2 e 3 demonstram que, na década de 1980, o ritmo de crescimento populacional de Aparecida de Goiânia foi superior ao próprio ritmo da capital de Goiás, fator que a levou a se tornar a segunda mais populosa cidade goiana e a alcançar o terceiro maior PIB do Estado no ano de 2011 e 2012, segundo dados do IMB (2012).

Analisando os dados apresentados nas Figuras 2 e 3, é possível realizar algumas assertivas sobre a expansão da população em Aparecida de Goiânia em comparação com a própria capital. Entre 1980 e 2010, enquanto Goiânia atingia quase o dobro da população, Aparecida de Goiânia decuplicava seus habitantes. 0 aumento populacional está articulado ao avanço da conurbação que se intensificou ao longo das últimas três décadas, o que fez com que a população identificada com Goiânia estabelecesse moradia no município de Aparecida de Goiânia.

0 vínculo desse município em relação à capital forneceu um novo destino produtivo no ano de 2014, pois Aparecida de Goiânia passou a ser reconhecida

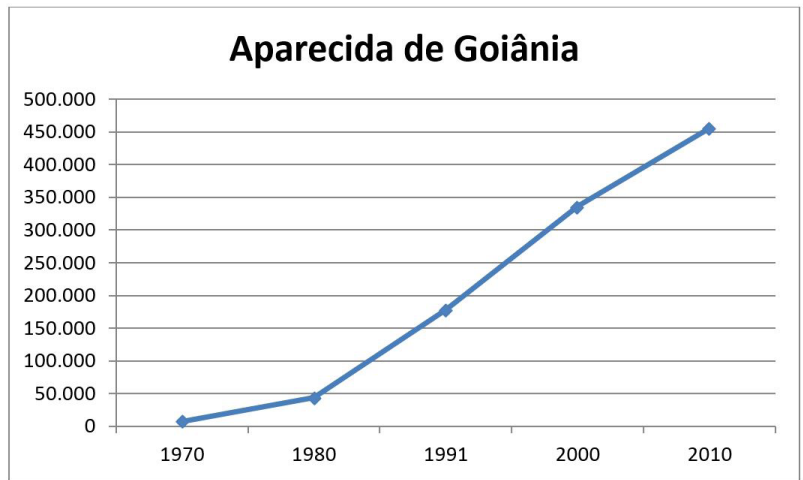

Figura 2 - Crescimento populacional de Aparecida de Goiânia, Estado de Goiás (em milhares de habitantes) Fonte: IBGE $(1970,1980,1991,2001,2010)$.

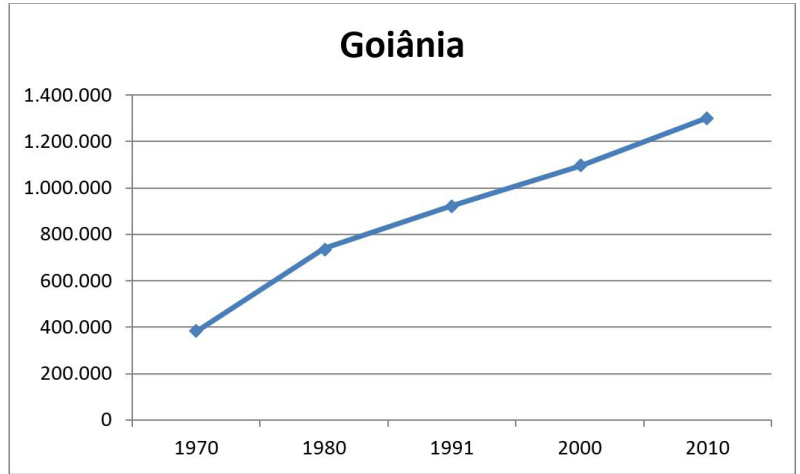

Figura 3 - Crescimento populacional de Goiânia, Estado de Goiás (em milhares de habitantes)

Fonte: IBGE $(1970,1980,1991,2001,2010)$. 
como uma cidade promissora economicamente. Em pesquisa realizada pela consultoria Urban Systems, publicada em 30 de abril de 2014 na revista Exame, Aparecida de Goiânia aparece como uma das dez melhores cidades em desenvolvimento econômico do Brasil. A pesquisa, intitulada "As melhores cidades para os negócios", mostra que as transformações recentes na dinâmica produtiva local impulsionaram Aparecida de Goiânia ao sétimo posto no ranking nacional, com uma nota de 5,77, em uma escala de 0 a 14 - Parauapebas, no Estado do Pará, aparece em primeiro lugar com nota 7,46. Considerando que a cidade paraense está inserida no fluxo impressionante de migração em busca de riquezas devido à presença da maior província mineral do mundo, a Serra dos Carajás, o resultado do município de Aparecida de Goiânia torna-se expressivo.

A posição de Aparecida de Goiânia no cenário econômico atual deve-se em grande medida pela fixação de diversas empresas na cidade ao longo da última década. Segundo dados da Secretaria da Fazenda do município, o número de indústrias instaladas cresceu $258 \%$ entre 2008 e 2014, passando de 590 para 2.012. Considerando a quantidade de empresas, os números são também relevantes: em 2008, havia 5.870; em 2014, 17.052.

Essa presença de novas empresas e indústrias, bem como a própria conurbação com a capital do Estado, insere em Aparecida de Goiânia outras relações de produção e circulação de mercadorias, de pessoas e também de símbolos, que contribuem para a formação de novas identidades e configuração de outras vivências urbanas.

Alguns questionamentos surgem diante dessa grande transformação na dinâmica produtiva do município, visto que a instalação de novas empresas e indústrias evidencia novos tempos de desenvolvimento e uma consequente demanda por ocupação de áreas que passam a ser consideradas urbanas. Nessa seara, a presente pesquisa volta-se para a observação da forma como a administração pública local pensa e realiza a gestão dos objetos que promovem trocas simbólicas e acontecimento cultural, a partir da constituição de locais destinados especificamente para esses fins.

Enquanto no aspecto populacional e econômico ocorreram significativas alterações, observou-se que não houve incremento substancial na destinação de espaços públicos voltados para a cultura, mesmo atingindo os seus atuais 500 mil habitantes. Durante a coleta de informações da pesquisa, não foram diagnosticados, por exemplo, nenhum teatro minimamente equipado para as artes cênicas, nenhuma galeria de arte de fato concebida para tal e raros espaços públicos destinados às outras expressões artísticas. Como garantia de eventos culturais, a cidade conta apenas com um grande espaço, o Centro Cultural José Barroso, que abriga quase todas as atividades culturais organizadas pelo poder público ou por grandes produtores culturais.

\section{Perfil e comportamento dos grupos, artistas e entidades destinadas à cultura}

Entre os meses de fevereiro de 2003 e junho de 2015, realizaram-se diversos momentos de busca por informações e dados sobre os grupos, os artistas, as entidades e os locais de práticas culturais em Aparecida de Goiânia. Durante o período de pesquisa empírica e de determinação do universo a ser pesquisado, organizaram-se informações provenientes de órgãos oficiais, de organizações não governamentais e também por meio do contato com grupos, artistas e produtores que participam da cena cultural de Aparecida de Goiânia. Ao longo desse tempo, mais de 300 grupos/artistas em atividade foram identificados, além de cerca de 80 entidades e 70 locais dinamizadores da cultura no município. Esses números podem ser considerados expressivos, visto que até o momento não há dados oficiais que congreguem as diversas manifestações culturais em uma única plataforma de acesso ao público.

Diversas estratégias foram traçadas no intuito de identificar e manter contato com os atores culturais constituídos como universo de pesquisa. Esses números foram alcançados por meio de atividades de campo envolvendo alunos - os quais, ao utilizarem mormente as redes sociais, organizaram essas informações - de cursos técnicos integrados ao ensino médio oferecidos pelo Instituto Federal de Goiás. Com o apoio da Secretaria Municipal de Cultura e Turismo e por meio de encontros pessoais com os representantes dos grupos ou com os próprios artistas, incrementou-se o universo a ser pesquisado. 0 apoio dessa Secretaria foi de extrema importância para que fossem encontrados mais cadastros em entidades e outras instituições que também exerciam atividades relacionadas à cultura no município. 
A título de ilustração vale ressaltar ainda a gentileza de entidades e de órgãos como: Serviço Brasileiro de Apoio às Micro e Pequenas Empresas (SEBRAE/GO, 2012), Secretaria de Ação Social, Academia Aparecidense de Letras, Conselho Municipal de Assistência Social (CMASAP, 2013), Conselho Municipal dos Direitos da Criança e do Adolescente (CMDCA, 2012). Tivemos acesso também, ao Cadastro de artistas participantes do evento Talentos da Terra (Aparecida de Goiânia, 2013), ao Cadastro de artistas do Festival Cultural de Aparecida de Goiânia (2012), ao Cadastro de grupos e artistas participantes do Movimento Mais Cultura (2013) e aos Cadastros Gerias das Associações de Bairros de Aparecida de Goiânia (AMAP, 2013) e outros documentos fornecidos por entidades que mobilizam e dinamizam a cultura em Aparecida de Goiânia. Após o recebimento dessas cadastros e listagens, as informações foram filtradas para que fossem identificados os nomes daqueles que realizavam ações voltadas para a cultura no município, assim como os grupos e os artistas presentes nas entidades.

Outra estratégia de trabalho constituiu-se na realização de entrevistas e na aplicação de questionários com artistas, grupos, produtores e entidades, momento em que foram feitos registros fotográficos dos grupos, artistas e entidades visitados. Essa estratégia se desenrolou durante 12 meses, em conjunto com o processo de chamamento nas redes sociais para que os grupos e os artistas se cadastrassem em um formulário on-line. Atualmente, o processo de organização das informações se dá por meio da tabulação dos dados provenientes desses formulários on-line, cujo preenchimento pode ser feito a qualquer momento, garantindo continuidade na atualização dos dados.

Os contatos realizados em órgãos públicos, ou a partir de indicação dos próprios grupos ou entidades culturais, forneceram uma alternativa para a criação de um mecanismo para que a pesquisa obtivesse uma amostra segura. Tendo como referência os locais de residência dos grupos e artistas, e também das entidades identificadas, buscou-se atingir todas as regiões administrativas, definidas pela Secretaria de Planejamento de Aparecida de Goiânia (Figura 4). De acordo com o quantitativo de grupos/artistas/ entidade encontrado em cada região administrativa, foram realizadas a tabulação dos questionários e a

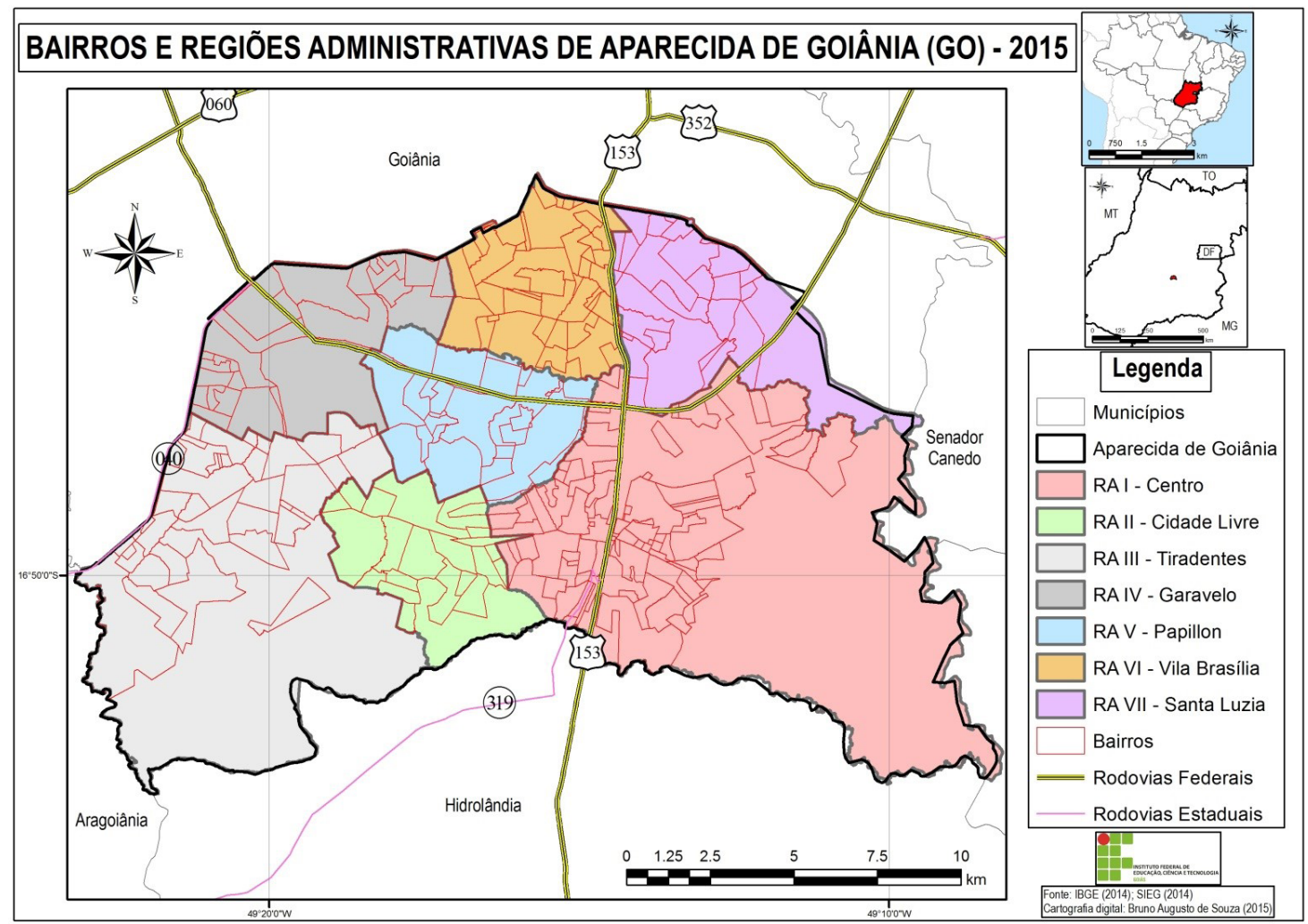

Figura 4 - Divisão das regiões administrativas do município de Aparecida de Goiânia, Estado de Goiás Fonte: Secretaria de Planejamento de Aparecida de Goiânia. 
análise das entrevistas de 38 grupos/artistas e de 12 entidades dinamizadoras da cultura. Acrescentou-se à pesquisa outro objetivo relacionado à presença dos artistas e de grupos identificados no mundo digital. Entre os 300 grupos/artistas do universo do trabalho, apareceram 121 perfis em algum tipo de rede social ou canais digitais de divulgação. Foram observadas páginas destinadas à música, sites, blogs e, especificamente, a rede social Facebook. A forma de utilização das ferramentas digitais pelos artistas e pelos grupos tornou-se outro foco do projeto de pesquisa, constituindo-se como outra variável a ser pensada na discussão sobre as possíveis territorialidades encontradas em Aparecida de Goiânia - o tópico final deste artigo trata desse tema de maneira mais detida.

Destaca-se aqui que, apesar da obtenção de dados importantes sobre a prática cultural de Aparecida de Goiânia, o intuito do projeto não é somente a catalogação de todos esses grupos e entidades, pois uma ação desse tipo seria obsoleta, levando-se em conta que há uma grande flutuação entre os grupos e os artistas locais no que se refere à manutenção da prática cultural. 0 projeto pretendeu atentar para os locais que esses grupos/artistas/entidades realizam suas práticas, para que, em um segundo nível, fosse possível pensar as relações urbanas que ganham particularidades a partir da inserção da atividade digital.

Ao extrair, do universo de 300 artistas/grupos, o número de 121 sujeitos que possuem algum tipo de ambiente digital publicado na internet e de 38 artistas/grupos entrevistados, evidenciaram-se características específicas que foram organizadas em três dimensões: o perfil dos 38 artistas e grupos entrevistados, o comportamento deles e o comportamento digital dos 121 sujeitos que possuem ambiente digital específico, ou seja, a forma de utilização das redes sociais como estratégias de divulgação e também de ocupação urbana.

A Figura 5 apresenta uma síntese dos elementos que fazem parte do perfil dos artistas e dos grupos entrevistados. Os resultados aparecem com uma referência numérica à tabulação dos dados realizada ao longo do processo de tratamento e seleção de informação. Entretanto, no âmbito desta pesquisa, é necessário que se considere esse tipo de gráfico como uma aproximação das tendências observadas, sem se restringir aos percentuais exatos alcançados. Os percentuais foram mantidos nos gráficos apenas para oferecer uma referência e maior facilidade de visualização dos resultados obtidos nas entrevistas e também nas análises dos ambientes digitais. Optou-se

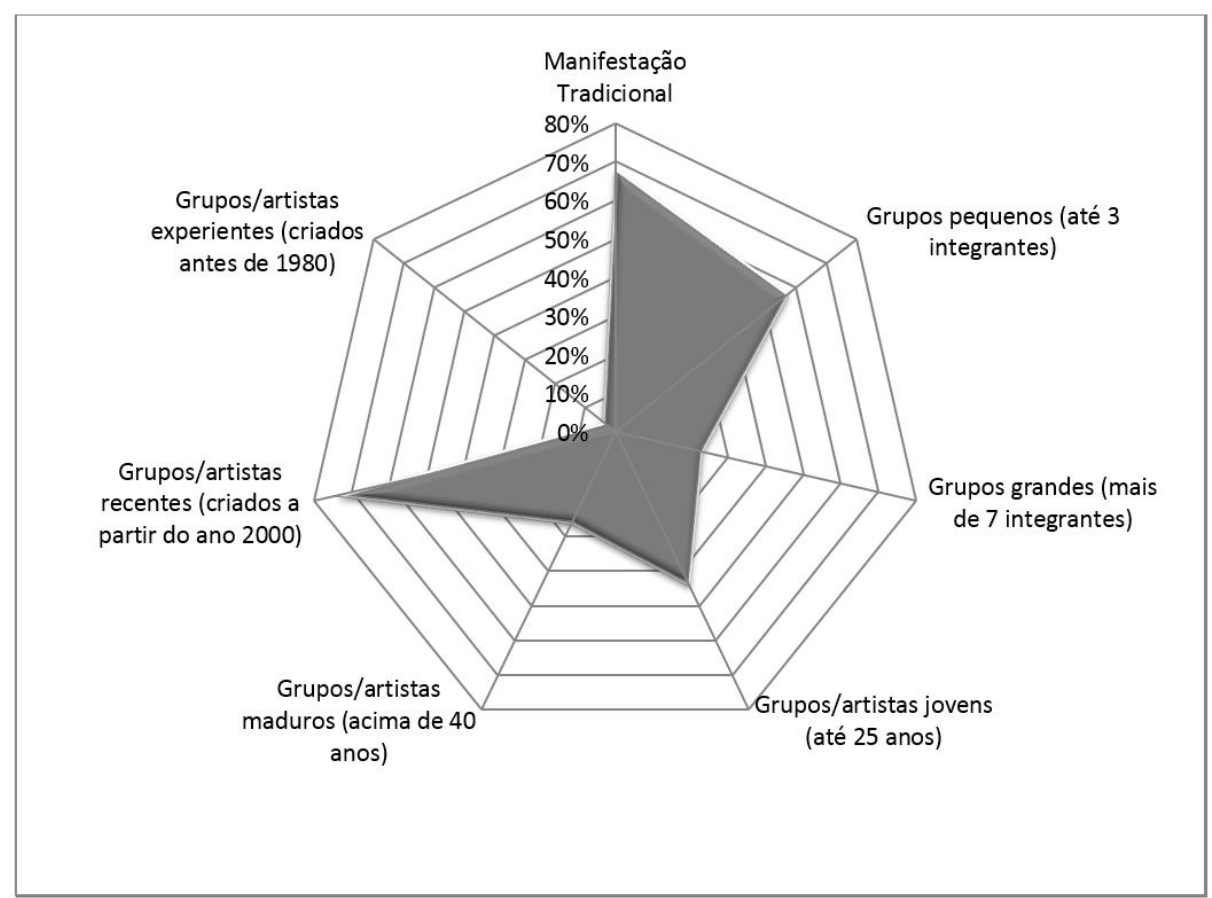

Figura 5 - Perfil dos entrevistados

Fonte: Elaborado pelo autor a partir de dados obtidos ao longo do desenvolvimento da presente investigação. 
pelo formato de gráfico radar por possibilitar cruzar informações de perguntas distintas. Nos gráficos aqui presentes, houve uma seleção dos resultados mais relevantes de cada questionamento realizado.

Como pode ser observado na Figura 5, entre os artistas e grupos entrevistados, nota-se uma clara relação ao pertencimento a uma manifestação tradicional, que é evidenciada na presença dos grupos de quadrilha, de Folia de Reis, de catira, dos músicos sertanejos, dos grupos de teatro e de outras expressões culturais. Independente da faixa etária ou da modalidade de expressão cultural, tem-se uma autodeclaração de pertencimento à tradição por quase $68 \%$ dos entrevistados.

Mesmo nos grupos considerados por esta pesquisa como recém-criados ou em fase de consolidação, ou seja, os grupos que iniciaram suas atividades entre os anos 2000 e 2014, que somam 73\%, há um chamado à tradição, cuja afirmação ocorre também entre os grupos compostos, majoritariamente, por indivíduos jovens, a saber, que possuem faixa etária até 25 anos e que somam $44 \%$ dos entrevistados.

Em relação à periodicidade da prática cultural dos grupos/artistas, apareceram dois padrões mais evidentes de respostas: um primeiro composto por aqueles que se apresentam semanalmente ou diariamente e um segundo composto por aqueles que se apresentam mensalmente ou esporadicamente, como pode ser observado na Figura 6. Isso leva a entender que há grande parte de indivíduos ainda não sustentando seus cotidianos com o trabalho relacionado à cultura; portanto, ainda à margem da cultura reconhecida pelos órgãos oficiais.

Para difundir a prática, mais de $75 \%$ utilizam a internet como veículo prioritário de divulgação do trabalho, seguido por $18 \%$ que usam formas orais de divulgação, a partir de contatos pessoais, apelidados na pesquisa de "boca a boca", como podem ser observados na Figura 6. Há aqui um caminho para pensar as raízes da resistência estimuladas pelo uso de redes digitais, articuladas às formas mais antigas de contatos entre os indivíduos. Isso se dá, certamente, por serem formas mais acessíveis financeiramente e por serem também formas de diálogo direto em alguma medida.

Um fator importante que a pesquisa levantou se refere à restrita utilização dos espaços públicos pelos artistas e grupos. Quando perguntados sobre quais locais utilizavam para realizar seus ensaios, $86 \%$ responderam que eram locais privados. Quando a pergunta se referiu aos locais de apresentação propriamente dita, 67\% disseram que ainda se restringiam aos locais privados. Aqui vale uma explicitação sobre esses dados: nessa questão, os entrevistados puderam escolher mais

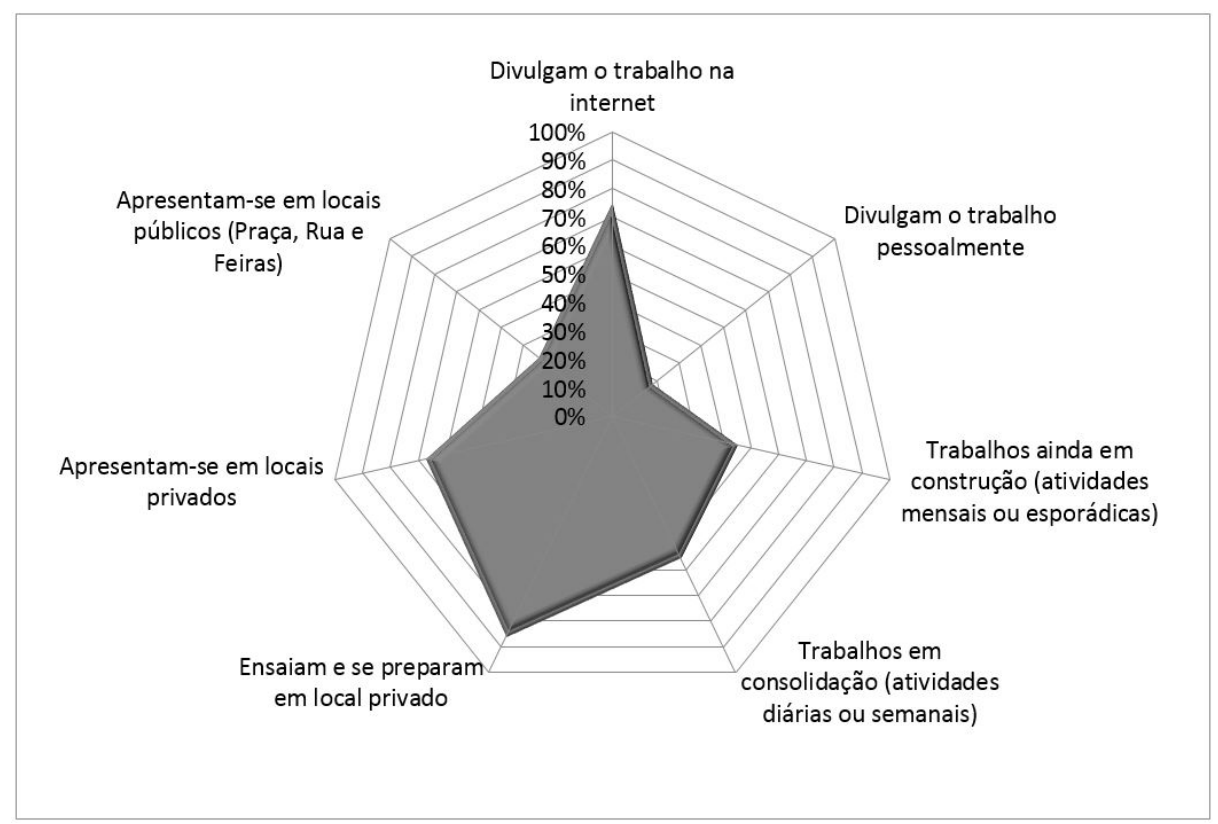

Figura 6 - Comportamento dos grupos/artistas entrevistados

Fonte: Elaborado pelo autor a partir de dados obtidos ao longo do desenvolvimento da presente investigação. 
de uma alternativa, entre rua, praça, feiras, espaços religiosos, bares e outras localidades, que foram citadas nominalmente. Para atingir os percentuais expressos na Figura 6, foi feita uma tabulação geral de todas as citações dos artistas e dos grupos para que se alcançassem tais índices. Pode-se compreender essa questão como sendo os locais que majoritariamente os artistas e os grupos se manifestam.

Na etapa atual da pesquisa, há uma organização dos dados de forma a garantir que os próprios envolvidos com a cultura de Aparecida de Goiânia e o público ampliado da rede mundial de computadores tenham acesso ao projeto. Alguns dados foram selecionados para a publicização, além de informações e imagens específicas dos grupos e dos artistas, bem como divulgação das entidades e dos locais identificados. Esses grupos, artistas, locais e entidades estão apresentados em dois blogs ${ }^{2}$ do projeto, assim como em uma interface com uma comunidade aberta criada no Facebook para facilitar o diálogo entre as partes interessadas.

\section{Caminhos para pensar a resistência em rede na cidade}

Como reflexão em curso na contemporaneidade, pode-se perguntar: ainda há tempo para resistir, ou melhor, no mundo contemporâneo, caberia uma atenção aos processos resistentes que se desdobram no cotidiano das cidades? Talvez seja um desejo fora do tempo esperar que os acontecimentos locais ganhem significados livres de um apelo global. Há que se perguntar sobre o local como "[...] um espaço restrito, bem delimitado, no interior do qual se desenrola a vida de um grupo ou de um conjunto de pessoas" e que, por ser restrito, "[...] possui um contorno preciso, a ponto de se tornar baliza territorial para os hábitos cotidianos" (Ortiz, 1999, p. 54).

Ortiz propõe que o local não paira livre das interferências das escalas nacionais e globais, e não percebe as escalas como excludentes nem como antíteses (Ortiz, 1999). 0 desafio é detectar permanências nas instâncias dos cotidianos das cidades que se exprimem como locais, mas a resistência é dinâmica, mesmo em processo de marcação de permanências. A chamada

\footnotetext{
${ }^{2}$ Mapa Cultural de Aparecida de Goiânia (2015) e Manifestações Culturais de Aparecida de Goiânia (2015).
}

sociedade em rede - o dilema existencial por excelência dos humanos que passaram a experimentar o planeta por inteiro - não esgarçou todas as possibilidades de configuração de resistências, que, mesmo convivendo com os traços globais, cravam significados locais. Apesar da contínua intenção das corporações e dos estados em estabelecer relações globais de interesse, não se pode esquecer de que " 0 que caracteriza o novo sistema de comunicação, baseado na integração em rede digitalizada de múltiplos modos de comunicação, é a sua capacidade de inclusão e de abrangência de todas as expressões culturais" (Castells, 2002, p. 460) e, por assim dizer, de todas as escalas de acontecimento. Por ora, o que se pode inferir é que a tensão entre as energias globais e os fluxos locais está certamente nos primeiros capítulos de uma longa história. Afirmar a falência do local em nome do global ou afirmar o local como resistência imediata ao global não é o caminho que se pretende seguir.

Quando se afirma aqui a resistência, assume-se o risco de pensar a "[...] inclusão e a abrangência de todas as expressões culturais" em sua dinâmica localizada na objetivação dos indivíduos - no caso aqui estudado, nos indivíduos que se põem a fazer cultura na cidade. Sabe-se que há uma massificação da cultura que estimula "[...] vetores poderosos de dominação, a ponto de se articularem em nível planetário", o que "pressupõe acomodações e conflitos" (Ortiz, 1999, p. 63) nos lugares. Entretanto, no processo de acomodação e de conflitos, convivem conjunções e disjunções que se desdobram nos limites da conformação. Os recortes possíveis passam pela admissão do social vivido corporalmente nas cidades, as quais representam o contato entre esse corpo orgânico, que só pode ser evidenciado na escala local, expresso na paisagem, e o mundo em suas dimensões simbólicas, que penetram e ultrapassam os lugares.

A cidade como objetivação da vida urbana, percebida parcialmente nas parcas garantias que a paisagem fornece, acaba por se tornar palco de excentricidades e, no confluir das normas sociais, ganha ares de confrontamento. Visitar os limites de uma globalização que pretende generalizar padrões de consumo e de difusão de símbolos não é entendê-la como menos capaz de realizar o projeto; é, na verdade, compreendê-la a partir de seus fluxos marginais. Se os lugares tornam-se "fantasmagóricos", como afirma Anthony Giddens, por serem "[...] penetrados e moldados em termos de influências sociais bem distantes deles" 
(Giddens, 1991, p. 27), é preciso ressaltar que eles também respondem de forma a catapultar para o mundo alguns traços de reconhecimentos locais, principalmente a partir de utilização de ferramentas digitais, como nos casos dos diversos textos, vídeos e imagens que se tornaram mundiais instantaneamente, mesmo criados em realidades locais.

A globalização para Giddens pode ser definida como "[...] a intensificação das relações sociais em escala mundial, que ligam localidades distantes de tal maneira que acontecimentos locais são modelados por eventos ocorrendo a muitas milhas de distância e vice-versa". É possível percebê-la, por meio de um processo dialético, como a oportunidade para que acontecimentos locais possam se "[...] deslocar numa direção anversa às relações muito distanciadas que os modelam" (Giddens, 1991, p. 69-70). A tensão é evidente, pois quanto mais experimentamos um mundo global, com processos intensos de pasteurização dos saberes e padronização dos costumes, mais percebemos processos sólidos de buscas por autenticidades, os quais são a afirmação da resistência, como no caso dos grupos e dos artistas de Aparecida de Goiânia que se autodeclaram tradicionais.

A dinâmica global se repete como recorrente fluxo de marcas de reconhecimento. Se em um primeiro momento se restringia à esfera econômica, na contemporaneidade o processo de "acomodação e conflito" entre o local e o global se encarrega de oferecer ao mundo suas próprias versões culturais. "As ações são cada vez mais estranhas aos fins próprios do homem e do lugar. Daí a necessidade de operar uma distinção entre a escala de realização das ações e a escala de seu comando" (Santos, 1999, p. 65). Em Aparecida de Goiânia, vive-se uma confluência de escalas de comando. Os gotejamentos globais são sentidos na inserção de novos objetos técnicos a serviço de demandas que extrapolam as necessidades locais. Atualmente, as escalas global, nacional e local se acomodam em Aparecida de Goiânia: uma espécie de novo presente está em curso, com a chegada das novas indústrias e empresas, potencializadas pelo surgimento aligeirado de diversos shopping centers, além da implantação recente de instituições federais de ensino, como o Instituto Federal de Educação, Ciência e Tecnologia de Goiás e o novo campus da Universidade Federal de Goiás, e ainda a construção de um aeroporto executivo.
Esses novos objetos técnicos, muitas vezes vindos de outras "escalas de comando", recebem novas funções, as quais estabelecem com os moradores outra rede de significados. Milton Santos (1999, p. 82) afirma que a existência histórica deste tipo de objeto

[...] depende de sua inserção numa série de eventos - uma ordem vertical - e sua existência geográfica é dada pelas relações sociais a que o objeto se subordina, e que determinam as relações técnicas ou de vizinhança mantidas com outros objetos - uma ordem horizontal.

Caberia perguntar em que medida esse recente contato com dinâmicas globais de investimentos estaria acarretando modalidades peculiares de ocupação dos espaços urbanos em Aparecida de Goiânia, buscando as raízes das relações que esses objetos estabelecem com os sujeitos que habitam a cidade. Como afirma Bruno Latour: "Mesmo uma rede ampla continua a ser local em todos os pontos" (Latour, 1994, p. 114). 0 fato local transporta a linguagem da tradição em seus diversos pontos, erguendo permanência e códigos de compreensão limitados às esferas próximas de convívio - no caso desta pesquisa, convívio cultural inerente ao acontecimento da dinâmica da cidade de Aparecida de Goiânia, evidenciada inclusive por sua proximidade à capital do Estado.

A Figura 7 trata dos acontecimentos culturais que se circunscrevem às práticas cotidianas e corriqueiras dos grupos e dos artistas da cidade. Ela demonstra a localização das entidades/instituições que dinamizam a cultura de Aparecida de Goiânia, além de locais que foram recorrentemente citados pelos entrevistados ou identificados nas redes sociais. Há aqui uma rede nos moldes como pensa Latour, a qual se processa no local seguindo normas específicas criadas nas dimensões identitárias da existência de cada sujeito e de cada objeto - neste caso, como "híbridos de natureza e cultura" (Latour, 1994, p. 16) e ainda como híbridos de "objetos e ações" como na noção de espaço de Milton Santos (1999). Os pontos dispostos no mapa figuram como lugares híbridos de resistência e, ao se interligarem em uma espécie de rede não oficial dos acontecimentos culturais, tornam-se a resistência se territorializando.

Essas localidades são como objetos da cultura funcionando em rede. Pode-se inferir que os objetos científicos "[...] circulam simultaneamente enquanto sujeitos, objetos e discurso", afinal "As redes estão 


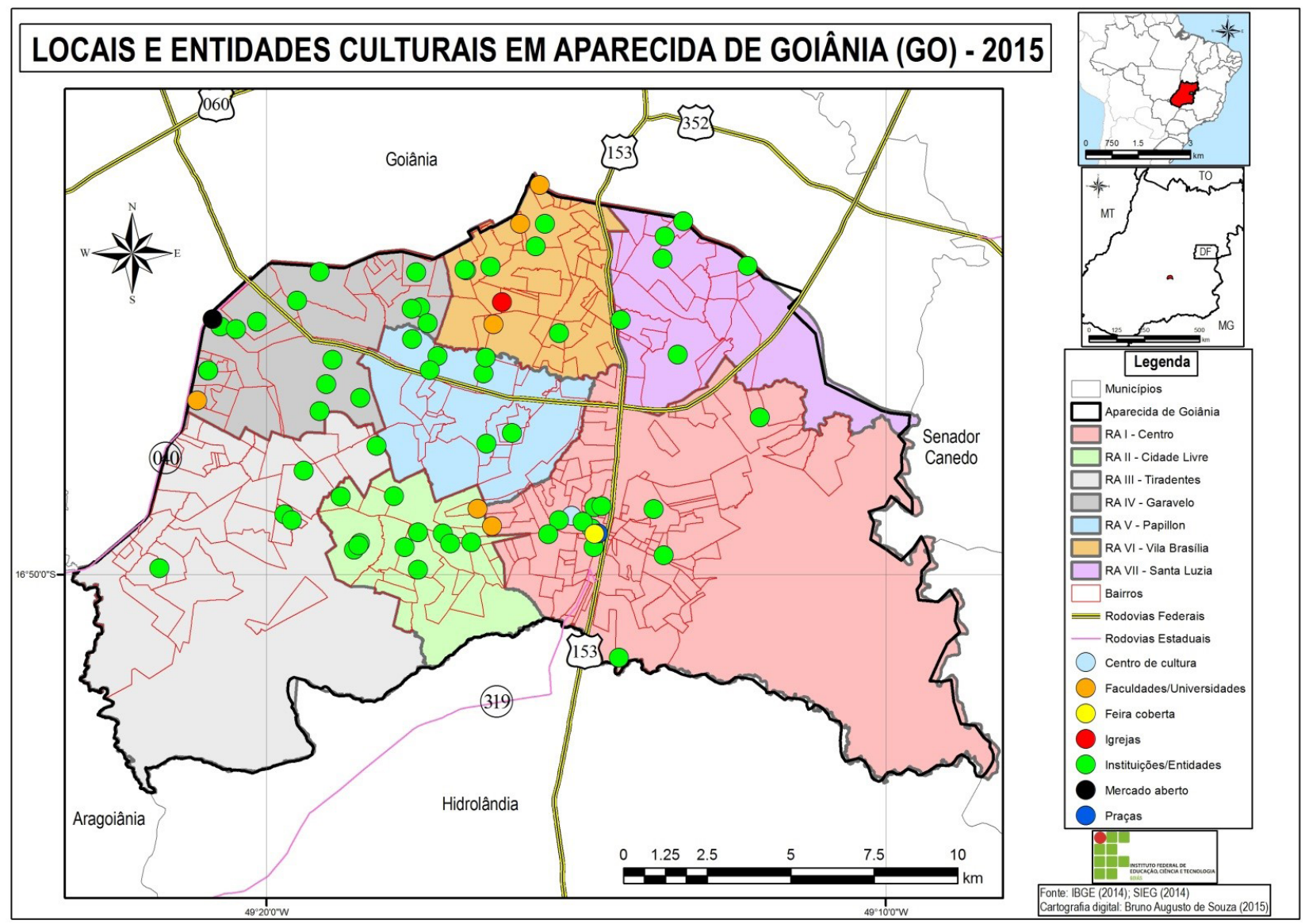

Figura 7 - Locais e entidades culturais citadas pelos artistas/grupos pesquisados Fonte: IBGE (2014).

preenchidas pelo ser. E as máquinas estão carregadas de sujeitos e de coletivos" (Latour, 1994, p. 65). Esse preenchimento viabilizado pelo ser esgarça-se em níveis, iniciando, no primeiro momento, corpóreo, biológico, de natureza incompleta, apontando, posteriormente, para o técnico e, por fim, estabelecendo relações simbólicas ao infinito, como na proposta de Berque (2009, p. 204) sobre o conceito de écoumène, cujo nascimento, em sua perspectiva, teria sido fruto de uma

[...] trajetividade pelo qual as funções do corpo, tornando-se humano, são exteriorizadas no ambiente. Assim se constitui nosso corpo medial. A estrutura que é configurada reparte o ser humano, por assim dizer, em duas metades, sendo que uma é nosso corpo animal, e a outra é nosso corpo medial. Esta divisão em duas metades, que amplia nosso ser do íntimo de nosso corpo animal até o horizonte de nosso mundo, é o momento estrutural de nossa existência. Esta é a nossa médiance.

Para Berque, o conceito de écoumène é vital para se compreender a existência humana. 0 "[...] écoumène é uma relação: a relação ao mesmo tempo ecológica, técnica e simbólica da humanidade à extensão terrestre" (Berque, 2009, p. 17). Não é possível garantir separações tão nítidas. Os corpos orgânicos que se ocupam das manifestações culturais são também corpos que operam técnicas, objetos que expressam o mundo das coisas e ao mesmo tempo o mundo dos símbolos. Como um híbrido,

[...] é frequentemente impossível ao homem comum distinguir claramente as obras da natureza e as obras dos homens e indicar onde termina o puramente técnico e onde começa o puramente social" (Santos, 1999, p. 81).

As redes digitais, seguindo normas semelhantes às das redes técnicas, como híbridas, contribuem 
para a geração de possibilidades de se elaborarem resistências no seio da cultura. Assim sendo, resistir não é somente guardar traços da tradição, mas é, acima de tudo, atentar-se aos sentidos locais que se desenrolam nas ruas, nas feiras e nas praças como gradações da existência do corpo ao símbolo.

Na pesquisa ora apresentada, somando-se os $75 \%$ de contatos com o público via internet e os $18 \%$ de contatos pessoais sem utilização de veículo expresso de comunicação, atingimos 93\% de utilização de mecanismos de divulgação que se restringem aos ambientes íntimos dos diálogos. Se, por um lado, ainda persiste uma compreensão de que os corpos não se encontram de forma íntima nas redes digitais, é por mero aprisionamento na visão física das coisas. Se, por outro lado, entende-se que o físico é um estágio a ser ultrapassado na existência, caminhando "do íntimo de nosso corpo animal até o horizonte de nosso mundo", não é possível descartar as similaridades entre as redes digitais e as redes técnicas. Os artistas e os grupos que promovem sua arte e divulgam seu trabalho via rede digital são presentes como formas vivas nas redes técnicas e, como tal, permanecem ao serem percebidos, resistem como ocupação material e também persistem como aparição digital.

\section{Tradição, território e ocupação resistente}

Em consonância com os mecanismos híbridos de existência, tem-se que, enquanto o espaço público não é ocupado pela maioria dos artistas de Aparecida de Goiânia, uma vocação para se guardar em tradição se avoluma a partir da utilização de redes técnicas e também de redes digitais. As entidades e os locais da cultura tornam-se, nessa perspectiva, pontos de estímulo à territorialização de resistências. Em síntese, a autodeterminação em nome da manifestação tradicional aludida pelos grupos e pelos artistas é, em conjunto com as redes técnicas e digitais, o escopo geral do surgimento do território que carreará o símbolo da resistência, em uma perspectiva contra-hegemônica, como afirma Haesbaert (2014, p. 54):

[...] espaço vivido, densificado, pelas múltiplas relações sociais e culturais que fazem do vínculo sociedade "terra", (ou natureza, se quisermos) um laço muito mais denso, em que os homens não são vistos apenas como sujeitos a sujeitar seu meio, mas como inter-agentes que compõem esse próprio meio e cujo "bem viver" (como afirmam os indígenas andinos) depende desta interação.

A territorialidade como condição de existência do território conjuga "materialidades e imaterialidades", fundando, assim, duas dimensões: a primeira "concreta e funcional" e a segunda "simbólica" (Haesbaert, 2014). Nesse processo que se sucede, conjuga-se parte das significâncias adotadas pelos artistas, grupos e entidades em sua expressão simbólica e também em sua dimensão corpórea ao mesmo tempo - nesse sentido, é corpórea pelo orgânico inerente aos indivíduos e também pela materialidade da cidade. Os locais tornam-se geradores e receptores de sinais do processo de acomodação e conflito vivido entre o global e o local. Dessa forma, funcionam como pontos de uma rede técnica e digital ao mesmo tempo, como híbridos conceituais, material e simbólico, e como dissipadores de uma mesma intenção no mundo prático.

Os locais que dinamizam práticas culturais de forma cotidiana, em meio à rede técnica a que pertencem, em conjunto com a comunicabilidade que se faz via rede digital, estabelecem resistência quando atuam na direção de se afirmar a tradição. A Figura 8 demonstra que esses locais de grupos, artistas e entidades que se espalham pela cidade de Aparecida de Goiânia vêm em processo de estruturação, pois $74 \%$ possuem menos de três anos de presença nas redes digitais, porém com $81 \%$ já divulgando o trabalho artístico, mesmo que ainda de forma esporádica (66\%).

0 caráter esporádico de atuação nas redes digitais é explicável exatamente por serem partícipes de uma rede técnica também em construção, a qual, por propor o conflito expresso como resistência tradicional, contra-hegemônica, encontra-se ainda em estágio inicial, o que é corroborado pelo fato de que $45 \%$ dos entrevistados também experimentaram um trabalho em construção, com apresentações esporádicas, como pode ser observado na Figura 6. Independente dos dados quantitativos, a Figura 8 demonstra que são usuários recentes das redes sociais, mas que, de forma já em parte profissional, fazem uso delas e divulgam seu trabalho. Em conjunto, surgem objetos técnicos que territorializam símbolos resistentes, como a dança típica das quadrilhas, a religiosidade da Folia de Reis e da congada, a música do campo, ressignificada como sertaneja, as linguagens dos grupos de teatro, os textos, a poesia e os movimentos diversos dos corpos.

O território da resistência, nessa medida, extrapola a materialização na paisagem por meio 


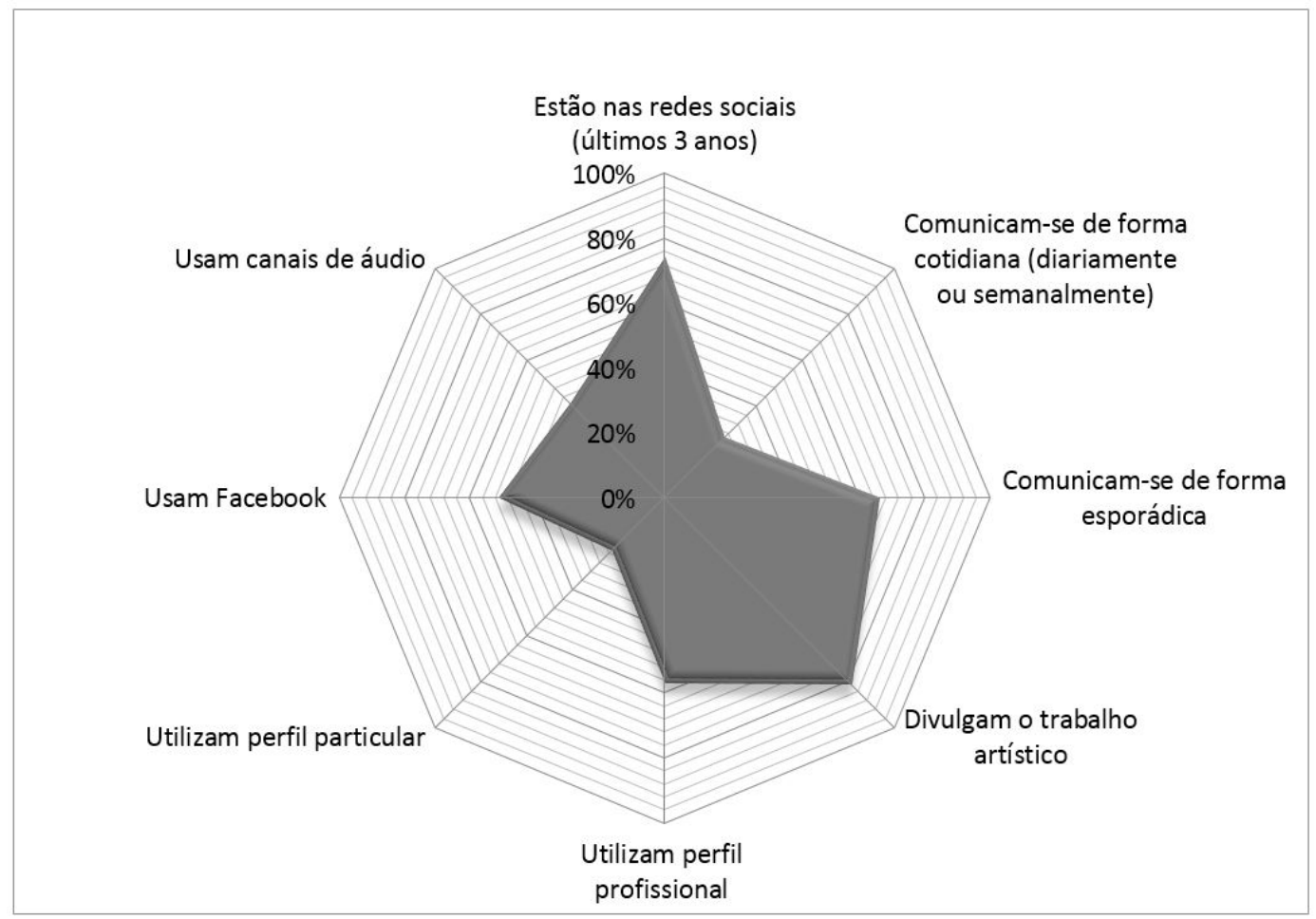

Figura 8 - Comportamento nas redes sociais

Fonte: Elaborado pelo autor a partir de dados obtidos ao longo do desenvolvimento da presente investigação.

de constituições de mecanismos de contraposição à força homogeneizadora, os quais os processos globais carregam nas diversas expressões da cultura. Em outros termos, a territorialidade resistente pela via das redes sociais digitais deflagra novas esferas de pertencimento. Neste movimento contínuo e duradouro, os símbolos locais vão se firmando, consolidando um modo de ser particular que tenciona a paisagem das cidades. A territorialidade participa simbólica e materialmente da constituição das paisagens, conferindo a elas certa hibridização, aproximando da compreensão defendida por Berque. Na perspectiva desse autor, a paisagem admite a materialidade, mas ela "[...] existe, em primeiro lugar na sua relação com o sujeito coletivo, a sociedade que a produziu, que a reproduz e a transforma em função de uma certa lógica" (Berque, 2004, p. 84).

Para Berque, a paisagem extrapola a instância meramente material, mesmo que se mantendo como marca que "expressa uma civilização", pois sua natureza é também como matriz que "participa dos esquemas de percepção, de concepção e de ação - ou seja da cultura" (Berque, 2004, p. 84). Em Aparecida de Goiânia, a paisagem ${ }^{3}$ demonstra os novos traços provenientes da força da metrópole em processo de consolidação com a dinamização da vida global, uma marca em firme construção. No deslizar da vida nas esquinas, garante também sua matriz com traços persistentes, que aponta para o centro dos códigos duradouros, tradicionais, aceitando novas sínteses e variações sobre os próprios códigos. Se como marca, a paisagem se apresenta em primeira instância de forma tátil, corpórea e material, em processo constante

\footnotetext{
${ }^{3}$ Milton Santos, ao longo de sua obra, por diversas vezes trata do conceito de paisagem. Na obra "A Natureza do Espaço", ele se ocupa de distinguir paisagem e espaço. Diz Milton Santos (1999, p. 83): "A paisagem é o conjunto de formas, que, num dado momento, exprimem as heranças que representam as sucessivas relações localizadas entre homem e natureza. 0 espaço são essas formas mais a vida que a anima". A ideia de se pensar a paisagem como marca, portanto material, e como matriz, dessa forma simbólica, é mais coerente para o modo como se entende aqui que a territorialidade se dá. Não é possível, no escopo pretendido neste texto, excluir da paisagem sua qualidade também híbrida ao abarcar marcas e matrizes.
} 
de acomodação e conflitos em relação às realidades globais, como matriz ela se aproxima da sua raiz, a profundidade existencial, no sentido atribuído por Besse, afinal “[...] não há paisagem sem profundidade, uma profundidade que se dá a ver sob a forma de uma presença nos longes, de um ser na distância que significa o espaço da vida" (Besse, 2006, p. 92).

Os territórios surgidos nas franjas da cultura oficial massificada, funcionando como rede de pessoas, produtos e símbolos, entram em contato direto com campos transversais de massa. 0 mundo atual despeja, na sociedade, paisagens que expressam uma civilização (Berque) em plena produção de fantasmagorias (Giddens), em que "[...] os espaços de cultura de massa são campos transversais", pois, na mesma intensidade e com simultaneidade, são "[...] geradores e destruidores de identidades" (Serpa, 2007, p. 37). São transversais na medida em que atravessam os lugares e penetram os diversos níveis de organização da sociedade, seja na produção material, seja na produção simbólica. Na forma como se propõe neste texto, a transversalidade massificadora encontra, também, com novas transversalidades, com múltiplas formas de apropriação da cidade.

Se a cidade é o lócus do contato entre o global e o local, é nesse mesmo contato que se processam os movimentos de retorno. A cada identidade quebrada e reconstituída ressurge a cidade em meio aos conflitos estabelecidos, sobretudo no campo simbólico. Isso ocorre porque "[...] a cidade gera um grau de liberdade incompatível com o nível de manipulação que a sociedade industrial e informacional contemporânea precisa para sobreviver" (Souza, 1997, p. 7). As territorialidades resistentes são potencializadas pela liberdade produzida no viver e no desdobrar da cidade, afinal esta não somente produz a liberdade, ela "[...] instaura redes de ação e de resistência contra a falta de liberdade, contra a desigualdade" (Souza, 1997, p. 7). As territorialidades que se instauram em meio às redes técnicas, digitais e simbólicas que se organizam a partir das práticas dos artistas, dos grupos e das entidades culturais constituem o grito rouco da liberdade; elas estimulam e agregam existências.

Em meio a essa existência, renovam-se os cânticos tradicionais, fundam-se territorialidades resistentes com práticas recobertas de histórias e, acima de tudo, sela-se um acordo com o presente, estabelecendo uma condição de chegada aos novos dias com garantias de outras permanências. A cidade de Aparecida de Goiânia vive suas tensões entre local e global, entre o corpo e o símbolo, e reescreve histórias nesses rastros deixados pela cultura. A presença digital nesse contexto eleva os anônimos à esfera de reconhecimento, atendendo não apenas a uma lógica global pura, mas como um híbrido que produz racionalidades locais, confundidas com a própria força resistente.

\section{Agradecimentos}

Ao Conselho Nacional de Desenvolvimento Científico e Tecnológico - CNPQ, ao Instituto Federal de Educação, Ciência e Tecnologia de Goiás - IFG e à Secretaria Municipal de Cultura e Turismo de Aparecida de Goiânia.

\section{Referências}

Aparecida de Goiânia. Prefeitura Municipal. Secretaria de Cultura e Turismo de Aparecida de Goiânia. (2013). Cadastro de artistas participantes do evento Talentos da Terra. Aparecida de Goiânia.

Aparecida de Goiânia. Prefeitura Municipal. Secretaria de Cultura e Turismo de Aparecida de Goiânia. (2012). Cadastro de artistas do Festival Cultural de 2012 de Aparecida de Goiânia. Aparecida de Goiânia.

Associações de Bairros de Aparecida de Goiânia - AMAP. (2013). Cadastros gerais das Associações de Bairros de Aparecida de Goiânia. Aparecida de Goiânia: AMAP.

Berque, A. (2009). Écoumène. Paris: Editions Belin.

Berque, A. (2004). Paisagem-Marca, Paisagem-Matriz: elementos da problemática para uma Geografia cultural. In R. L. Corrêa, \& Z. Rosendahl (Eds.), Paisagem, tempo e cultura (p. 84-91). Rio de Janeiro: Eduerj.

Besse, J. M. (2006). Ver a terra: seis ensaios sobre a paisagem e a Geografia. São Paulo: Editora Perspectiva.

Castells, M. (2002). A sociedade em rede. São Paulo: Paz e Terra.

Conselho Municipal de Assistência Social de Aparecida de Goiânia - CMASAP. (2013). Relação das entidades inscritas no CMASAP. Aparecida de Goiânia: AMAP.

Conselho Municipal dos Direitos da Criança e do Adolescente de Aparecida de Goiânia - CMDCA. (2012). Cadastro de entidades do CMDCA. Aparecida de Goiânia: AMAP. 
Giddens, A. (1991). As consequências da modernidade. São Paulo: Editora da Universidade Estadual Paulista.

Haesbaert, R. (2014). Viver no limite. Rio de Janeiro: Bertrand Brasil.

Instituto Brasileiro de Geografia e Estatística - IBGE. (1970). Dados obtidos no Sistema IBGE de recuperação automática - SIDRA. Recuperado em 20 de outubro de 2015, de http://www.sidra.ibge.gov.br/bda/tabela/listabl. asp? $\mathrm{z}=\mathrm{cd} \& 0=27 \& \mathrm{i}=\mathrm{P} \& \mathrm{c}=200$

Instituto Brasileiro de Geografia e Estatística - IBGE. (1980). Dados obtidos no Sistema IBGE de recuperação automática - SIDRA. Recuperado em 20 de outubro de 2015, de http://www.sidra.ibge.gov.br/bda/tabela/listabl. asp? $\mathrm{z}=\mathrm{cd} \& \mathrm{o}=27 \& \mathrm{i}=\mathrm{P} \& \mathrm{c}=200$

Instituto Brasileiro de Geografia e Estatística - IBGE. (1991). Dados obtidos no Sistema IBGE de recuperação automática - SIDRA. Recuperado em 20 de outubro de 2015, de http://www.sidra.ibge.gov.br/bda/tabela/listabl. asp? $\mathrm{z}=\mathrm{cd} \& \mathrm{o}=27 \& \mathrm{i}=\mathrm{P} \& \mathrm{c}=200$

Instituto Brasileiro de Geografia e Estatística - IBGE. (2001). Dados obtidos no Sistema IBGE de recuperação automática - SIDRA. Recuperado em 20 de outubro de 2015, de http://www.sidra.ibge.gov.br/bda/tabela/listabl. asp? $\mathrm{z}=\mathrm{cd} \& 0=27 \& \mathrm{i}=\mathrm{P} \& \mathrm{c}=200$

Instituto Brasileiro de Geografia e Estatística - IBGE. (2010). Dados obtidos no Sistema IBGE de recuperação automática - SIDRA. Recuperado em 20 de outubro de 2015, de http://www.sidra.ibge.gov.br/bda/tabela/listabl. asp? $\mathrm{z}=\mathrm{cd} \& \mathrm{o}=27 \& \mathrm{i}=\mathrm{P} \& \mathrm{c}=200$

Instituto Brasileiro de Geografia e Estatística - IBGE. (2014). Censo demográfico 2010. Rio de Janeiro: IBGE.

Instituto Mauro Borges de Estatísticas e Estudos Socioeconômicos - IMB. (2012). Produto Interno Bruto dos Municípios do Estado de Goiás, de 2012. Goiânia: IMB.
Recuperado em 20 de outubro de 2015, de http://www. imb.go.gov.br/pub/pib/pibmun2012/pibmun2012.pdf

Latour, B. (1994). Jamais Fomos Modernos: ensaio de antropologia simétrica. Rio de Janeiro: Nova Fronteira.

Manifestações Culturais de Aparecida de Goiânia. (2015). Aparecida de Goiânia. Recuperado em 20 de outubro de 2015, de http://gruposmapaculturaldeaparecida.blogspot. com.br/

Mapa Cultural de Aparecida de Goiânia. (2015). Aparecida de Goiânia. Recuperado em 20 de outubro de 2015, de http://mapaculturaldeaparecida.blogspot.com.br/

Movimento Mais Cultura. (2013). Cadastro de Grupos e artistas participantes do Movimento Mais Cultura. Aparecida de Goiânia.

Ortiz, R. (1999). Um outro território: ensaios sobre a mundialização. São Paulo: Olho D'água.

Santos, M. (1999). A natureza do espaço: técnica e tempo: razão e emoção. São Paulo: Hucitec.

Serpa, A. S. P. (2007). Culturas transversais: um novo referencial teórico-metodológico para a Geografia humanista e cultural? In S. Kozel, J. C. Silva \& S. F. Gil Filho (Eds.), Da percepção e cognição à representação: reconstruções teóricas da Geografia cultural e humanista (1, p. 36-56). São Paulo: Terceira Margem.

Serviço Brasileiro de Apoio às Micro e Pequenas Empresas - SEBRAE/GO. (2012). Cadastro de artistas locais realizado pela instituição. Goiânia: SEBRAE/GO.

Souza, M. A. A. (1997). Cidade: lugar e geografia da existência. In $5^{\circ}$ Simpósio Nacional de Geografia Urbana: Conferência de Abertura. Salvador.

Recebido: Jun. 18, 2015

Aprovado: Jan. 18, 2016 